\title{
A perversão, o desejo e o gozo: articulações possíveis
}

\author{
Perversion, desire and jouissance: \\ Possible articulations
}

\author{
Adelson Bruno dos Reis SANTOS \\ Vera Lopes BESSET ${ }^{1}$
}

\begin{abstract}
Resumo
Os autores procuram subsidiar aportes para uma discussão acerca da especificidade estrutural da perversão e sua relação com o desejo e com o gozo. Circunscrever o campo da perversão a partir de sua etiologia, delimitar os processos metapsicológicos capazes de objetivá-la e definir suas características específicas contrapostas às da neurose e da psicose, desde Freud, não constitui tarefa fácil. Ao estudar esse controverso construto teórico-clínico, os autores acentuam o quanto a perversão, na maioria das vezes, aparece como um conceito fronteiriço, tênue e de referências confusas no que diz respeito à sua especificidade estrutural. A proposta é avançar para além dos paradigmas freudianos, tendo como pano de fundo a dialética do desejo no ensino de Lacan. Existiria um caminho propiciador de uma articulação possível entre o desejo e o gozo?
\end{abstract}

Unitermos: Castração; Desejo sexual; Desvios sexuais.

\begin{abstract}
The authors seek to subsidize contributions to a discussion regarding the structural specificity of perversion and its relation to desire and jouissance. Circumscribing the field of perversion from its etiology, delimiting the metapsychological processes able to objectify it, and defining their specific features as opposed to neurosis and psychosis since Freud is not an easy task. By studying this controversial theoretical and clinical construct, the authors emphasize how perversion most often appears as a tenuous border concept, with confusing references in regard to its structural specificity. The proposal is to move beyond the Freudian paradigms, with the backdrop of the dialectic of desire in Lacan. Is there a way that would provide a possible link between desire and jouissance?
\end{abstract}

Uniterms: Castration; Sexual desire; Sexual deviations.

O tema da perversão agrega uma pluralidade conceitual que o articula em vários níveis e determinações múltiplas. Quanto ao desejo, também não se pode dizer que haja uma maneira unívoca de con- ceituá-lo e abordá-lo na literatura psicanalítica. Propõe-se, neste artigo, avançar para além dos paradigmas freudianos, delimitando uma etiologia da perversão fundamentada nos processos metapsicológicos capa-

\section{$\boldsymbol{\nabla} \mathbf{v} \boldsymbol{v}$}

1 Universidade Federal do Rio de Janeiro, Instituto de Psicologia, Programa de Pós-Graduação em Psicologia. Av. Pasteur, 250, Pavilhão Nilton Campos, Praia Vermelha, 22290-240, Rio de Janeiro, RJ, Brasil. Correspondência para/Correspondence to: A.B.R. SANTOS. E-mail: <adelsonbrunopsi@gmail.com>.

Artigo elaborado a partir da dissertação de A.B.R. SANTOS, intitulada "O desejo e o gozo na perversão: articulações possíveis". Universidade Federal do Rio de Janeiro, 2011. Apoio: Conselho Nacional de Desenvolvimento Científico e Tecnológico. 
zes de objetivá-la, tendo como pano de fundo a dialética do desejo no ensino de Lacan.

Em Freud, pode-se falar de desejos, no plural, e de suas realizações nos sonhos, nas formações de sintomas e no amor. A proposta lacaniana encontra-se na concepção do desejo a partir da falta acentuada numa dialética com o Outro. O desejo em Lacan se define em sua relação intrínseca com a necessidade e com a demanda: o homem deseja porque a satisfação de suas necessidades passa pelo apelo dirigido a um Outro, o que altera a satisfação, transformada em demanda de amor (Lacan, 1957-1958/1999).

Em razão de sua ligação com a ordem biológica, que não basta a si mesma, o amor, como relação com o Outro na qual o sujeito se aliena, permanece marcado por uma exigência de satisfação que não se dará no modo como é demandada. É nessa hiância entre a necessidade e a demanda que o desejo se situa: ele "se esboça na margem em que a demanda se rasga da necessidade" (Lacan, 1960/1998, p.828). Ele é um hiato, uma não coincidência entre sua causa e o objeto desejado. Ele opõe-se à noção de satisfação. O desejo é sua insatisfação; está sempre em referência à impossibilidade (Miller, 1997).

A demanda de amor é a experiência pela qual se recorta a relação do sujeito com a linguagem e o desejo. É no desejo do Outro, constituído a partir da linguagem, o único meio de o sujeito se sustentar (Lacan, 1960-1961/1992). Nesse sentido, esta investigação propõe uma retomada da teoria da constituição do sujeito como submetida à dimensão do desejo como desejo do Outro. A experiência esboçada mediante o estádio do espelho (Lacan, 1949/1998) enuncia uma relação com a exterioridade, com a falta. É a falta que revelará a dimensão da linguagem como o registro por meio do qual o Outro comparece para mediatizar e dar valor de existência ao sujeito. Tal condição marca toda a dialética do desejo; afinal, o drama do sujeito na linguagem é que ele faz aí a experiência de sua falta-a-ser (Lacan, 1954-1955/1979).

No Seminário $N$, ao trazer à tona a relação de objeto, introduzindo o falo como objeto privilegiado, Lacan (1956-1957/1995) abre um vasto campo para a problematização do desejo. A dinâmica da tríade imaginária mãe-criança-falo fará da castração o pilar do acesso ao desejo por evidenciar a falta e a incomple- tude. É o reconhecimento da castração como falta que confere ao falo sua função essencial na estruturação do desejo (Lacan, 1958/1998).

No Seminário V, Lacan (1957-1958/1999) acentua a questão fálica como fundamento da psicanálise ao instituir o falo como significante primordial do desejo na problemática edipiana: o Édipo se dará em torno do lugar conferido ao falo no desejo dos atores edipianos, numa dialética desenvolvida em torno do ser e do ter. Na medida em que o Édipo convoca esta relação dialética a encontrar um ponto de ancoragem no registro simbólico, ele se torna um processo estruturante para o sujeito."). O falo, portanto, é o significante privilegiado que se conjuga com o advento do desejo (Lacan, 1958/1998, p.699). Elemento central em torno do qual o desejo circula, ele é a referência que permite ao sujeito regular seu desejo em referência ao desejo do Outro.

É pela dialética do ser e do ter o falo que o sujeito se transpõe de uma posição de identificação com o falo da mãe a outra posição, de renúncia a tal identificação e de aceitação da castração. Esta operação que se dá no decorrer do processo de simbolização foi denominada por Lacan (1957-1958/1999) de metáfora paterna: O nome-do-pai é o significante que se condensa ao falo como significante do desejo que se apresenta para o sujeito sob a forma da castração.

O nome-do-pai opera como uma função simbólica estruturante, significada na fala da mãe como instância mediadora do desejo. A descoberta da dimensão que estrutura o desejo como submetido à lei do desejo do Outro é crucial para a significação dada pelo sujeito ao desejo da mãe. A percepção da mediação do desejo da mãe pela lei do pai provoca o desenlaçamento do sujeito de sua identificação fálica e, ao mesmo tempo, seu enlaçamento à lei do Outro. A metáfora paterna afasta a criança de sua alienação imaginária à mãe para conferir-Ihe a posição de sujeito desejante (Lacan, 19571958/1999). O nome-do-pai se apresenta como o significante que faz advir o sujeito dividido (\$), e a divisão é condição para o surgimento do desejo.

\section{A perversão e a dialética do desejo}

Observando o percurso teórico tal como apresentado, o interesse neste artigo se concentra em 
investigar como se configura a dialética do desejo tendo em vista a especificidade da estrutura perversa. Na perspectiva lacaniana, o ponto de ancoramento da estrutura perversa deve ser buscado no nível da identificação fálica quando o desejo da criança a conduz a se instituir como o único objeto possível do desejo da mãe. Todo o problema das perversões consiste em conceber como a criança, em sua relação com a mãe, "não por sua dependência vital, mas pela dependência de seu amor, isto é, pelo desejo de seu desejo, identifica-se com o objeto imaginário desse desejo, na medida em que a própria mãe o simboliza no falo" (Lacan, 1958/1998, p.561).

O desejo da criança se faz desejo encarnado pela mãe onipotente: por um lado em razão de uma sujeição àquela que lhe satisfaz todas as necessidades, por outro, em razão do capital de gozo que ela assegura à criança, que vai além da satisfação das necessidades. É essa dupla experiência que destina a mãe ao lugar do Outro, fazendo com que a criança apreenda o desejo materno como suporte essencial de sua dimensão identificatória. Na perversão, pode-se dizer, sobre a criança, que "é propriamente com o falo que ela de identifica" (Lacan, 1957-1958/1999, p.190). Trata-se de uma identificação que faz da mãe um Outro onipotente e a constitui como uma dimensão legisladora da ordem do desejo: "Toda a classificação das perversões deve se fundar nesse ponto. Qualquer que seja o valor das contribuições sobre a identificação com a mãe e a identificação com o objeto etc., o essencial é a relação ao falo" (Lacan, 1956-1957/1995, p.198).

A identificação fálica pode se enquistar num modo particular de economia do desejo que caracterizaria a estrutura perversa propriamente dita. Se a estase do desejo em torno da identificação fálica é inevitável, ela não deixaria de apresentar uma incidência decisiva, uma vez que é com base nisso que se configuraria a relação do perverso com a castração (Dor, 1991). O perverso desmentiria a castração em sua função de fazer advir a falta como causa do desejo. O pai simbólico, em sua função de embaixador da lei e da interdição, é precisamente a instância mediadora de que ele nada quer saber, na medida em que ela the exige o reconhecimento da ordem da falta no Outro. Se compete à função paterna introduzir, por sua mediação, o desejo como desejo do desejo do Outro, permaneceria o perverso cativo de uma economia desejante que o privaria do acesso ao desejo?

Circunscrever o campo da perversão a partir de sua etiologia, delimitar os processos metapsicológicos capazes de objetivá-la e definir suas características específicas contrapostas às da neurose e da psicose, desde Freud, não constitui tarefa fácil. Ao estudar esse controverso construto teórico-clínico, percebe-se o quanto a perversão, na maioria das vezes, aparece como um conceito fronteiriço, tênue e de referências confusas no que diz respeito à sua especificidade estrutural.

As primeiras publicações de Freud tendem a apresentar a perversão como uma vicissitude da pulsão, com regressão ou fixação a um estágio libidinal arcaico (Freud, 1905 [1991]/2005; 1905/2005). Entretanto, no decorrer de sua obra, ele procura aprofundar esta questão a partir do complexo de Édipo. A análise de Hans coloca para Freud (1909/2005) caminhos fecundos para o estudo da castração. É por meio desta análise que ele se depara pela primeira vez com o fenômeno da recusa. A partir da visão da perversão inserida na dialética edipiana, Freud a retira do rol das concepções puramente diferenciais e comparativas para atribuir a ela características específicas de uma posição subjetiva. Tal diretiva proporcionou um avanço considerável na solidificação dos fundamentos teóricos da perversão.

Em Fetichismo, Freud (1927/1996) apresenta o mecanismo próprio que possibilitará a instalação da posição perversa: o mecanismo da recusa (Verleugnung). A definição da perversão em relação a esse mecanismo provoca seu refinamento metapsicológico. Trata-se de uma saída para o conflito edípico contraposta à dissolução do mesmo pela via do recalcamento (Verdrangung), que configura a formação neurótica, e pela via da foraclusão (Verwerfung), conceito posteriormente introduzido por Lacan, que configura a formação psicótica.

Já em 1896, em uma de suas correspondências com Fliess - Manuscrito K -, Freud se perguntava o que, afinal, diferenciava uma perversão de uma neurose, encontrando dificuldades para estabelecer tal diferenciação. Um desdobramento possível para esta questão evidencia-se a partir da lógica da neurose como o negativo da perversão (Freud, 1905 [1901]/2005). Se, para Freud, estabelecer as fronteiras que delimitariam a perversão e a neurose em campos distintos e específicos deu-se de maneira confusa, pode-se dizer que, 
ao percorrer o ensino de Lacan, inicialmente, essa dificuldade se estabelece no que diz respeito à circunscrição dos campos diferenciais para a perversão e a psicose. Uma primeira leitura dos textos que compõem o chamado primeiro ensino de Lacan (Miller, 2003), mais especificamente do Seminário V (Lacan, 1957-1958/1999), leva a pensar em uma mesma dinâmica constitutiva, já que, em ambas as estruturas, o que está em jogo é a identificação ao falo. Contudo, encontram-se no decorrer do seminário supracitado diferenciações importantes que levam ao estabelecimento da especificidade da estrutura perversa.

Em linhas gerais, pode-se concluir que a perversão é marcada por uma cumplicidade libidinal materna em razão do gozo que a mãe assegura à criança, que vai além da satisfação de suas necessidades, e por uma complacência de um pai que não se faz intervir convenientemente pela lei de seu discurso. Sela-se, assim, um pacto de omissão diante da atuação de uma mãe sedutora (Lacan, 1957-1958/1999). Ocorreria, portanto, uma miniminização da mediação paterna, o que despojaria o pai de suas prerrogativas simbólicas para delegá-las à fala da mãe. Porém, é o fato desta delegação guardar referência à lei do pai que evita a entrada na psicose. Na perversão, a lei materna é referida à lei do pai, portanto, há lei, pois o perverso não poderia desmentir sem reconhecer antes o que deve ser desmentido. Por outro lado, na psicose, a lei materna não é referida à lei do pai; portanto, não há a lei do pai.

A cumplicidade libidinal da mãe e a complacência silenciosa do pai alimentarão na criança a certeza de sua identificação fálica capturada na fronteira da dialética do ser e do ter. Tal cumplicidade materna se desenvolveria a partir de uma sedução real junto à criança, que reconheceria os apelos da mãe como confirmação de seu desejo. Assim sendo, a mãe se comportaria de forma paradoxal no que diz respeito à intrusão paterna e ao desejo que ela supõe: ela não confirma o engajamento de seu desejo junto ao pai, contudo, não desmente sua eventualidade (Lacan, 1957-1958/1999).

Podem ser apontados dois elementos imaginários em jogo na construção perversa. Tais elementos estão em relação com a castração da mãe e com a 408 problemática do desejo da mãe pelo pai. O primeiro deles é que o pai é considerado responsável por uma castração, supostamente real, da mãe: se ela não tem pênis, é porque foi castrada pelo pai. Por outro lado, a mãe é culpada por ter-se comprometido com o pai ao desejar seu desejo, portanto, ela é cúmplice da castração (Lacan, 1957-1958/1999). Como saída para este impasse, o perverso imporia uma construção imaginária de compromisso na qual a mãe onipotente neutralizaria a incidência paterna, permitindo a ele comportar-se como substituto do único objeto de desejo que a faz gozar.

O que ocorreria na perversão é que o sujeito ficaria preso entre a mãe enquanto delegada da palavra do pai e a mãe sedutora e permissiva que deprecia a significação estruturante da lei do pai. Portanto, na medida em que a complacência silenciosa do pai autoriza a fala materna a se fazer representante da interdição, a criança é aprisionada em uma situação insolúvel. Situação entre uma mãe ameaçadora e proibidora, leva-e-traz da fala simbólica do pai, e uma mãe sedutora, que encoraja o gozo transformando em derrisão a significação estruturante da lei do pai.

Na perversão, tratar-se-ia de um enquistamento de toda a economia do desejo, devido à estagnação na identificação fálica. Isto tornaria o perverso incapaz de assumir uma posição faltante como simbolizável por meio da castração, daí a necessidade de desmenti-la. Desse modo, a possibilidade de aceitação da castração em sua função de fazer advir a falta como causa de desejo encontrar-se-ia obstruída. Por essa reiterada negação da castração, o perverso propor-se-ia à promoção imaginária de uma mãe fálica numa tentativa de neutralização da diferença dos sexos e da falta que ela acentua.

Tal realidade imporia um perfil particular à economia do desejo. O paradoxo no qual se instala a problemática perversa diante da lei do pai, negando-a e, ao mesmo tempo, reconhecendo-a, tende a se impor como única função possível de regulamentação do desejo. Só a renúncia ao objeto primordial do desejo seria a condição que salvaguardaria a possibilidade do próprio desejo, dando-Ihe um novo estatuto induzido pela mediação da função paterna. A partir disso, o perverso seria então cativo de uma economia desejante insustentável, abstraindo-se do acesso ao desejo, demonstrando que a única lei que reconhece é a lei 
imperativa de seu próprio desejo e não a do desejo do Outro.

Esforçando-se para manter o empreendimento de uma possibilidade de gozo que se libertaria do desejo como causa significante, o perverso parece não ter outra saída senão o desafio da lei e sua transgressão. Desautorizando a lei do pai, ele procuraria demonstrar que o seu desejo não passa pela lei do desejo do Outro. Sua lei é a lei que o ordenaria a buscar o gozo por todos os meios, sem se deixar deter por nenhum limite, por nenhuma lei. Trata-se do gozo como dever, como imposição.

\section{Do gozo absoluto à castração}

O conceito lacaniano de gozo pode ser considerado como uma fecunda reformulação da metapsicologia freudiana. Pode-se recordar, independentemente dos vocábulos usados, certos momentos em que o gozo é destacado por Freud no espaço de sua clínica, como, por exemplo, a voluptuosa expressão que ele observa no Homem dos Ratos (Freud, 1909/2007) quando recorda o relato da tortura, ou o júbilo percebido no rosto de seu netinho quando se encontra envolvido em brincar com um objeto, o famoso carretel, da mesma forma que o próprio menino é jogado pela alternância entre a presença e a ausência da mãe (Freud, 1920/1989); ou ainda o gozo infinito que experimenta Schreber ao constatar a transformação paulatina de seu corpo em um corpo feminino (Freud, 1911/2006).

Pode-se dizer que o gozo encontra-se enunciado na teoria freudiana como um esforço de reencontro do objeto perdido. Ora, não é possível partir de nenhuma tentativa de articulação entre o gozo e a busca pelo objeto perdido sem acentuar o caráter sempre insatisfeito de uma tentativa de fundar o significante da relação sexual. Assim sendo, a teoria lacaniana introduz dois conceitos fundamentais: o de "falo" e o de "relação sexual impossível". O gozo sexual não é, em lugar algum, simbolizado nem simbolizável. Ele é real. Nesse sentido, não há sujeito do gozo sexual. A fórmula "não há relação sexual"funciona, a partir de 1969, como uma chamada à ordem permanente dessa ausência de significante sexual. Quanto ao falo, pode-se dizer que não há equivalência entre o homem e a mulher no tocante à castração, uma vez que, para simbolizar o sexo da mulher, o simbólico carece de material (Bessa \& Besset, 2009). Para o homem, a função do pai da horda que goza de todas as mulheres (Freud, 1913/1989) assegura uma função de exceção, não submetida à castração e a partir do qual pode ser fundado o universal da Lei. Para a mulher, as coisas não se passam assim, pois há para ela um ponto de indeterminação que resulta da ausência do significante sexual. Com a fórmula "a mulher não existe", Lacan (1959-1960/2008) sublinha o impossível do universal da mulher que a coloca diante de um gozo infinito, decorrente do significante da falha do lugar do Outro.

O gozo é, no inconsciente e na teoria, um lugar vazio de significantes. É nesse sentido que a teoria lacaniana propõe a inexistência da relação sexual. A priori pode-se compreendê-la como uma ausência de união genital entre o homem e a mulher. Contudo, é um erro interpretá-la assim. A fórmula significa que não existe relação simbólica entre um suposto significante do gozo masculino e um suposto significante do gozo feminino. Isto porque, no inconsciente, não há significantes que signifiquem o gozo de um e do outro, cada qual imaginado como gozo absoluto. O gozo, em sua forma infinita, é um lugar sem significante e sem marca que o singularize. Se a palavra relação quer dizer relação entre dois significantes que signifiquem o gozo, então, não existe relação alguma, seja ela absoluta ou relativa, quer se trate de um gozo ilimitado ou limitado (Nasio, 1993).

Do gozo absoluto à castração: esse é o sentido da rota freudiana que acaba dando o lugar central na psicopatologia ao complexo de castração e suas vicissitudes. A castração reorganiza por retroação todo o acontecido anterior ao estabelecimento desta primazia fálica. Se a primeira teoria freudiana do psiquismo propunha um sujeito governado pelo princípio do prazer e no qual a sexualidade era uma impureza e uma tensão trazida pela sedução do adulto perverso, a segunda mostra o incremento das excitações como algo que se origina no interior, que adere a fantasmas e que requer desse adulto que se integre dialeticamente no aparelho de gozo.

Haveria uma incompatibilidade entre gozo e lei, que é lei da linguagem, que obriga a desejar e abdicar do gozo, convertendo as aspirações ao gozo em termos de discurso articulado e de vínculo social. O conflito 
entre o sujeito e o Outro seria fatal se não existisse uma instância simbólica que regulasse os intercâmbios. É a lei do Outro, consubstancial à linguagem, que impõe as limitações e as perdas do gozo. O sujeito deve renunciar ao gozo em troca de uma promessa de outro gozo próprio do sujeito da lei. O gozo originário, anterior à lei, é um gozo interdito que deveria ser inclinado e substituído por uma promessa de gozo fálico, consecutiva à aceitação da castração, fazendo com que lhe seja lícito procurar aquilo que perdeu. O gozo fálico é resultante da inclusão do sujeito como súdito da lei no registro simbólico, como sujeito da palavra submetido às leis da linguagem. Segundo Miller (2010) a lei que separa do gozo da mãe e põe o nome-do-pai nesse lugar, ordena desejar; este desejo encontra sua possibilidade de realização por meio do viés do amor como sentimento encarregado de suprir a inexistência da relação sexual e de trazer de volta o gozo a que se teve de renunciar.

Pelo reconhecimento do Outro da linguagem o sujeito advém à existência. Para Braunstein (2007), o Outro Ihe indica de várias maneiras que a existência recebida não é gratuita; ela deve ser paga com a moeda da renúncia ao gozo. É preciso resignar-se com a perda que implica entregar algo real em troca de uma recompensa que é simbólica, um quantum de gozo em troca das precárias certezas que dão as palavras de amor e os signos sempre falazes que emanam do Outro, de um Outro que também se pergunta porque haveria ele de renunciar a seu gozo:

[...] a clínica mostra os efeitos devastadores que se produzem naqueles a quem a existência é dada gratuitamente, aqueles que não tropeçam com um Outro que seja demandante [...] aqueles que recebem antes de pedir, fora do regime de intercâmbios, quando a satisfação antecipada das demandas desfaz a própria possibilidade do desejo (Braunstein, 2007, p.56).

Do gozo originário que o infante experimenta não resta, senão, uma nostalgia que o mitifica, já que é irrecuperável em sua forma. Mas como ninguém se resigna de bom grado à renúncia que lhe é exigida, o gozo rechaçado insiste. $O$ perdido não é esquecido, mais ainda, é o fundamento mesmo de um desejo infinito de recuperação que se manifesta no discurso

410 do inconsciente. Do gozo originário, pela intromissão necessária do Outro e de sua Lei, que exigem que tal gozo seja renunciado, fica uma falta-a-ser, que é o desejo.

Com Lacan (1998/1960), aprende-se que o desejo é uma defesa que mantém o gozo em seu horizonte de impossibilidade. Graças à função do pai, ele se dobra à lei. $O$ desejo e a lei são a barreira no caminho do gozo. Nos seminários A angústia e Os quatro conceitos fundamentais da psicanálise, Lacan (1962-1963/2005; 1964/2003) ocupou-se da questão da relação de oposição e de passagem do gozo ao desejo. Para que tal conciliação de opostos seja possível o sujeito deverá mostrar-se desejante, habitado por uma falta que fecha a via ao gozo do ser e abre a de um acesso ao gozo do Outro. O encontro do desejo com o gozo só pode ter lugar sob o signo da castração. Entre o desejo e o gozo haveria, se não o amor, a angústia. Se é o amor que produz a condescendência do gozo ao desejo, parte-se da premissa de que a ética da psicanálise concerne à conjugação do desejo com o gozo e, portanto, com o amor.

\section{Os perversos também amam?}

A assertiva lacaniana de que "amar é dar aquilo que não se tem" instaura o amor no campo da falta (Lacan, 1960-1961/1992). Mas como pode alguém dar aquilo que Ihe falta? O sujeito da psicanálise, tal qual Lacan (1960/1998) o define, é tomado como algo cujo modo de existir é a barra, a abolição, a incompletude, operações pelas quais ele se constitui e se realiza. É nesse sentido que o amor implica o domínio do "não-ter". Para amar é necessária a aceitação da condição de "não-todo", o reconhecimento de que "não se tem"; é preciso admitir a castração como aquilo que torna possível o enlaçamento à lei do Outro. O lugar do amor deve ser situado a partir do encontro sempre faltoso do sujeito com o Outro, na ilusão apaziguadora da completude perdida, na busca incansável da satisfação primeira e num profundo anseio de seu retorno sob o signo do desejo. Como aquilo que faz suplência à relação sexual, ele revela um esforço sempre precário de fazer frente ao real da falta. Contudo, o amor pertence ao domínio do mito, uma vez que não encontra sua satisfação na realidade. Logo, ele não é real: é um engodo; é a falsidade resultante do "assujeitamento" do 
desejo ao desejo do Outro. Para Ferreira (2004), ele seria, então, uma tentativa de fazer desaparecer sempre um efeito de logro, na medida em que o que falta ao amante o amado também não tem.

Numa época em que o amor se torna líquido, evidenciando a fragilidade dos laços humanos (Bauman, 2006), cada sujeito é levado a reinventar sua relação com ele, num labirinto de mal entendidos no qual a saída não existe. O amor parece encontrar seu entrave no imperativo do gozo. Assim sendo, o que é possível dizer acerca do amor na perversão, considerando que o perverso é aquele que, desmentindo a castração, renega a falta para viver para o gozo? Contrariando o domínio do "não-ter", ele se apresenta como aquele que tem o saber sobre o desejo e sobre o gozo, conciliando-os e resolvendo sua contradição originária. Daqui derivam as dificuldades para se definir a relação do perverso com o amor.

Contudo, uma relação difícil não significa ausência nem impossibilidade. Segundo Braunstein (2007), pensar a relação entre o amor e a perversão a partir de seus limites e impasses permite ampliar a compreensão acerca do específico de um amor que denuncia as convenções unificadoras e que desmente a falta ao invés de basear-se nela. Ao falar do amor na perversão propõe-se, neste artigo, uma inversão da lógica lacaniana para perguntar: e quando amar é dar aquilo que se tem? Seria isso possível?

Condição para o amor, o desejo no perverso é convertido em vontade de gozo; uma vontade que não é livre-arbítrio, uma submissão acrítica a uma norma absoluta. Uma vontade que faz do gozo o princípio racional da ação, que não nasce da decisão elaborada de um querer, mas de uma coação que exige escapar da lei do Édipo e da castração. Entretanto, Lacan (1962-1963/2005) adverte que a vontade de gozo na perversão fracassa em relação ao exercício do desejo. O desejo poderia ser chamado vontade de gozo se, frente a esta, ele não se colocasse de maneira tão imponente:

Mesmo na perversão, na qual o desejo se dá como aquilo que serve de lei, ou seja, como uma subversão da lei, ele é, efetivamente, suporte de uma lei. Se há uma coisa que hoje sabemos do perverso, é que aquilo que aparece externamente como uma satisfação irrefreada é uma defesa, bem como o exercício de uma lei, na medida em que esta refreia, suspende, detém o sujeito no caminho do gozo. A vontade de gozo no perverso, como em qualquer outro, é uma vontade que fracassa, que depara com seu próprio limite, seu próprio freio, no exercício mesmo do desejo (Lacan, 1962-1963/2005, p.166).

A perversão parece interpor um ponto de interseção entre amor e gozo que não necessariamente se excluem. É possível que, ao se deparar com o desejo, o gozo encontre seu próprio limite. O desejo não está ausente no perverso. Mesmo que precariamente, é o desejo que o move, pois a renúncia ao gozo se produziu: por isso não é um psicótico. Ele sabe que deve renunciar ao gozo, "mas mesmo assim..." busca implacavelmente alcançá-lo. O perverso é um sujeito dividido pelo desejo, contudo, o desejo, que é fator da fenda no sujeito, "sem dúvida se conformaria em se dizer vontade de gozo", pois "ele já começa derrotado, fadado à impotência" (Lacan, 1962-1963/2005, p.784).

Por mais que o desejo se converta em vontade de gozo, nem por isso deixa de ser o meio de defesa do perverso contra o gozo: "Também ele se defende, à sua maneira, em seu desejo. Pois o desejo é uma defesa, proibição de ultrapassar um limite no gozo" (Lacan, 1960/1998, p.839). Miller (2000) diz que o desejo vem efetuar uma significantização do gozo; um gozo mortificado pela identificação fálica que entrava o livre curso de desejo e que deve ser transposto para o significante. Trata-se, essencialmente, do apagamento do gozo pelo significante que o anula e o restitui sob a forma de desejo significado: "O gozo, por um lado, não é outra coisa que o desejo, que é, ao mesmo tempo, desejo morto" (Miller, 2000, p.91).

Para Miller (2010) o gozo condescende ao desejo na tentativa de suprir a ausência da relação sexual colocando em evidência a oposição entre o enquistamento do gozo autoerótico e o amor que mostra sua abertura ao Outro. Mas como esse gozo pode entrar na dimensão do Outro? Como se passa do gozo ao desejo do Outro? Para que possa aflorar essa condescendência é necessário que o gozo tenha sido recusado, perdido, renunciado, separado do corpo pelo Outro do significante e da Lei. A condição do amor é a supressão do gozo originário. Seu pano de fundo é o inconsciente. É um derivado da Lei de proibição do incesto que faz da mãe um objeto proibido para o gozo e que, pela via da marca fálica, induz ao desejo, esse desejo que encontra apenas objetos evocadores do perdido. 
Se, com base em Lacan, entende-se que o amor consiste em "dar o que não se tem", dar a castração, a carência no gozo; se, novamente em Lacan, aceita-se que o amor é o único que pode fazer com que o gozo condescenda ao desejo, então não se pode negligenciar a difícil relação entre o amor e a perversão. Contudo, conforme adverte Braunstein (2007), a intenção não deve ser a de decidir se os perversos também amam, mas de compreender o específico de um amor que desmente a falta em vez de basear-se nela.

\section{Considerações Finais}

O perverso renegaria tanto a impotência quanto a impossibilidade afirmando a possibilidade do gozo. A essência de sua vida amorosa consistiria em oferecer o gozo sem passar pelo desejo, pois o consentimento e a convergência com o desejo do Outro restringiriam sua satisfação. Deslocando-se do amor para o erotismo, o perverso torna-se um predestinado ao exercício de uma vontade que atua como imperativo universal. Uma vontade que o leva a viver para o gozo para apoderar-se dele, organizá-lo, administrá-lo.

Um sujeito é algo instável, vacilante. O lugar do sujeito é o da incerteza, já que ele é o efeito do que se articula na cadeia significante. O perverso se recusaria a identificar-se com algo tão precário, tão dependente da resposta do Outro. Ele é a causa pela qual o Outro se divide. Ele necessita de um Outro que experimente a divisão subjetiva como efeito de sua manipulação, um Outro que não é bom quando é complacente, mas quando é violentado, resistente, suplicante; pois, quando o Outro consente, a perversão se dissipa.

Considerada assim, a perversão é totalmente o contrário do que o próprio perverso pensa que é e faz. É o perverso que é o objeto e sua vítima o sujeito. 0 paradoxo é que o perverso, ele mesmo, querendo ser o dono da situação, imaginando sê-lo, é o objeto de sua paixão. Ao tentar equivaler-se ao objeto-instrumento que assegura o gozo do Outro, ele tenta anular-se como sujeito, efeito do significante, uma possível tentativa de rejeitar sua dor de existir resultante de sua falta-a-ser. Mas, como essa falta é concebida como um efeito estrutural da castração, apesar de todas as suas tentativas, o perverso estaria constantemente se confrontando com

412 ela. Porque esta falta retorna do Outro, ele não nega de modo algum a existência do Outro, mas procura provocar o outro naquilo que ele possui de mais íntimo até obter sua angústia.

Por fim, pode-se dizer que a perversão surge como uma sutura antinômica com o discurso psicanalítico, em seu desígnio de não ocultar a fenda. É sua característica a pretensão de obturar tudo o que provém do não-sabido do sujeito. Encontrar-se com o inconsciente revelaria ao perverso a insondável rachadura que o leva a ceder seu desejo. Sua única possibilidade, na perspectiva da psicanálise, é que na perseguição de seu gozo encontre-se com seu limite. É difícil substituir a vontade de gozo pelo desejo, uma vez que a única coisa que se pode propor para essa transição é o reconhecimento de uma impossibilidade real no final do caminho; "mas mesmo assim..., cabe à psicanálise prosseguir no desenvolvimento de dispositivos teórico-clínicos que Ihe permitam aproximar-se de respostas para as questões relativas à problemática da perversão.

\section{Referências}

Bauman, Z. (2006). Amor líquido: sobre a fragilidade dos laços humanos. Rio de Janeiro: Jorge Zahar.

Bessa, G., \& Besset, V. L. (2009). Encontros e desencontros: ensaio sobre o não há. Latin American Journal of Fundamental Psychopathology, 6(2), 97-114. Recuperado em outubro 12, 2010, disponível em <http://www. psicopatologiafundamental.org/uploads/files/ latin_american/v6_n2/encontros_e_desencontros_ ensaio_sobre_o_nao_ha.pdf>.

Braunstein, N. (2007). Gozo. São Paulo: Escuta.

Dor, J. (1991). Estrutura e perversões. Porto Alegre: Artes Médicas.

Ferreira, N. P. (2004). A teoria do amor. Rio de Janeiro: Jorge Zahar.

Freud, S. (1989). Tótem y Tabú. In Obras completas (Vol. 13). Buenos Aires: Amorrortu. (Originalmente publicado en 1913).

Freud, S. (1989). Más allá del princípio del placer. In Obras completas (Vol. 18). Buenos Aires: Amorrortu. (Originalmente publicado en 1920).

Freud, S. (1996). Fetichismo. In Obras completas (Vol. 21). Buenos Aires: Amorrortu. (Originalmente publicado en 1927).

Freud, S. (2005). Fragmento de analices de um caso de histeria. In Obras completas (Vol. 7). Buenos Aires: Amorrortu. (Originalmente publicado en 1905 [1901]).

Freud, S. (2005). Tres ensayos de la teoría sexual. In Obras completas (Vol. 7). Buenos Aires: Amorrortu. (Originalmente publicado en 1905). 
Freud, S. (2005). A propósito de un caso de neurosis obsesiva. In Obras completas (Vol. 10). Buenos Aires: Amorrortu. (Originalmente publicado en 1909).

Freud, S. (2006). Puntualizaciones psicoanalíticas sobre un caso de paranóia. In Obras completas (Vol. 12). Buenos Aires: Amorrortu. (Originalmente publicado en 1911).

Freud, S. (2007). A propósito de un caso de neurosis obsesiva. In Obras completas (3a ed., Vol. 10). Buenos Aires: Amorrortu. (Originalmente publicado en 1909).

Lacan, J. (1979). O seminário livro Il: o eu na teoria de Freude na técnica da psicanálise. Rio de Janeiro: Jorge Zahar. (Originalmente publicado em 1954-1955).

Lacan, J. (1992). O seminário livro VIII: a transferência. Rio de Janeiro: Jorge Zahar. (Originalmente publicado em 1960-1961).

Lacan, J. (1995). O seminário livro IV: a relação de objeto. Rio de Janeiro: Jorge Zahar. (Originalmente publicado em 1956-1957).

Lacan, J. (1998). O estádio do espelho como formador da função do eu. In Escritos. Rio de Janeiro: Jorge Zahar. (Originalmente publicado em 1949).

Lacan, J. (1998). A significação do falo. In Escritos. Rio de Janeiro: Jorge Zahar. (Originalmente publicado em 1958).

Lacan, J. (1998). Subversão do sujeito e dialética do desejo no inconsciente freudiano. In Escritos. Rio de Janeiro: Jorge Zahar. (Originalmente publicado em 1960).
Lacan, J. (1999). O seminário livro V: as formações do inconsciente. Rio de Janeiro: Jorge Zahar. (Originalmente publicado em 1957-1958).

Lacan, J. (2003). Os quatro conceitos fundamentais a psicanálise. In Outros escritos. Rio de Janeiro: Jorge Zahar. (Originalmente publicado em 1964).

Lacan, J. (2005). O seminário livro X: a angústia. Rio de Janeiro: Jorge Zahar. (Originalmente publicado em 1962-1963).

Lacan, J. (2008). O seminário livro VII: a ética da psicanálise. Rio de Janeiro: Jorge Zahar. (Originalmente publicado em 1959-1960).

Miller, J.-A. (1997). O desejo. In Lacan elucidado: palestras no Brasil. Rio de Janeiro: Jorge Zahar.

Miller, J-A. (2000). Os seis paradigmas do gozo. Opção Lacaniana, 26-27, 87-105.

Miller, J-A. (2003). O último ensino de Lacan. Opção Lacaniana, 35, 5-24.

Miller, J-A. (2010). Uma conversa sobre o amor. Opção Lacaniana, 1(2), 1-32. Recuperado em julho 25, 2010, disponível em <www.opcaolacaniana.com.br>.

Nasio, J. D. (1993). Cinco lições sobre a teoria de Jaques Lacan. Rio de Janeiro: Jorge Zahar.

Recebido em: 27/7/2011

Versão final em: 22/12/2011

Aprovado em: 24/1/2012 